\title{
Enzymatic Crosslinked Gelatin 3D Scaffolds for Bone Tissue Engineering
}

Echave, Mari Carmen; Pimenta-Lopes, Carolina; Pedraz, José Luis; Mehrali, Mehdi; Dolatshahi-Pirouz, Alireza; Ventura, Fransesc; Orive, Gorka

Published in:

International Journal of Pharmaceutics

Link to article, DOI:

10.1016/j.jpharm.2019.02.043

Publication date:

2019

Document Version

Peer reviewed version

Link back to DTU Orbit

Citation (APA):

Echave, M. C., Pimenta-Lopes, C., Pedraz, J. L., Mehrali, M., Dolatshahi-Pirouz, A., Ventura, F., \& Orive, G. (2019). Enzymatic Crosslinked Gelatin 3D Scaffolds for Bone Tissue Engineering. International Journal of Pharmaceutics, 562, 151-161. https://doi.org/10.1016/j.ijpharm.2019.02.043

\section{General rights}

Copyright and moral rights for the publications made accessible in the public portal are retained by the authors and/or other copyright owners and it is a condition of accessing publications that users recognise and abide by the legal requirements associated with these rights.

- Users may download and print one copy of any publication from the public portal for the purpose of private study or research.

- You may not further distribute the material or use it for any profit-making activity or commercial gain

- You may freely distribute the URL identifying the publication in the public portal

If you believe that this document breaches copyright please contact us providing details, and we will remove access to the work immediately and investigate your claim 


\section{Accepted Manuscript}

Enzymatic Crosslinked Gelatin 3D Scaffolds for Bone Tissue Engineering

Mari Carmen Echave, Carolina Pimenta-Lopes, José Luis Pedraz, Mehdi

Mehrali, Alireza Dolatshahi-Pirouz, Fransesc Ventura, Gorka Orive

PII:

S0378-5173(19)30175-9

DOI:

https://doi.org/10.1016/j.ijpharm.2019.02.043

Reference:

IJP 18181

To appear in: $\quad$ International Journal of Pharmaceutics

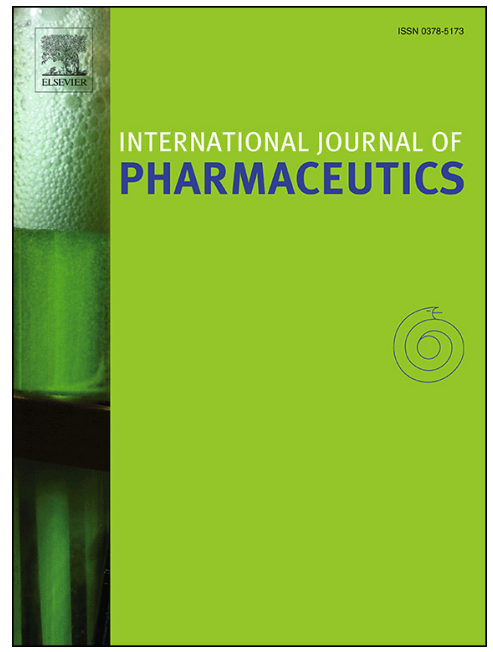

Received Date: 21 December 2018

Revised Date: $\quad 17$ February 2019

Accepted Date: $\quad 27$ February 2019

Please cite this article as: M.C. Echave, C. Pimenta-Lopes, J.L. Pedraz, M. Mehrali, A. Dolatshahi-Pirouz, F. Ventura, G. Orive, Enzymatic Crosslinked Gelatin 3D Scaffolds for Bone Tissue Engineering, International Journal of Pharmaceutics (2019), doi: https://doi.org/10.1016/j.ijpharm.2019.02.043

This is a PDF file of an unedited manuscript that has been accepted for publication. As a service to our customers we are providing this early version of the manuscript. The manuscript will undergo copyediting, typesetting, and review of the resulting proof before it is published in its final form. Please note that during the production process errors may be discovered which could affect the content, and all legal disclaimers that apply to the journal pertain. 


\section{Enzymatic Crosslinked Gelatin 3D Scaffolds for Bone Tissue Engineering}

Authors:

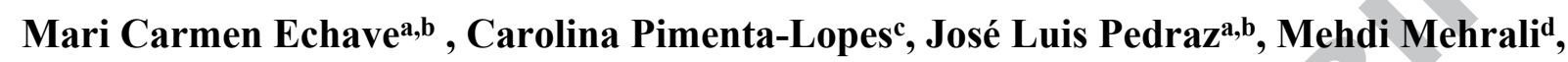
Alireza Dolatshahi-Pirouz ${ }^{\mathrm{d}}$, Fransesc Ventura ${ }^{\mathrm{c}}$, Gorka Orive ${ }^{\text {a,b,e,f,* }}$

\section{Affiliations:}

${ }^{a}$ NanoBioCel Group, Laboratory of Pharmaceutics, School of Pharmacy, University of the Basque Country UPV/EHU, Paseo de la Universidad 7, Vitoria-Gasteiz 01006, Spain.

${ }^{b}$ Biomedical Research Networking Centre in Bioengineering, Biomaterials and Nanomedicine (CIBER-BBN), Vitoria-Gasteiz, Spain.

'Departament de Ciències Fisiològiques, Universitat de Barcelona, IDIBELL, C/ Feixa Llarga s/n 08907 Hospitalet de Llobregat, Spain.

dTechnical University of Denmark, DTU Nanotech, Center for Nanomedicine and Theranostics, $2800 \mathrm{Kgs}$, Denmark.

eUniversity Institute for Regenerative Medicine and Oral Implantology - UIRMI (UPV/EHUFundación Eduardo Anitua), Vitoria, Spain; BTI Biotechnology Institute, Vitoria, Spain.

fSingapore Eye Research Institute, The Academia, 20 College Road, Discovery Tower, Singapore.

*Corresponding author: Gorka Orive. Associate Professor of Pharmacy \& Pharmaceutical Technology. Faculty of Pharmacy; University of the Basque Country (UPV /EHU); Paseo de la Universidad 7; 01006 Vitoria-Gasteiz (Spain). E-mail: gorka.orive@ehu.eus

Twitter:@gorka_orive 


\section{Abstract}

Bone tissue engineering is an emerging medical field that has been developed in recent years to address pathologies with limited ability of bones to regenerate. Here we report the fabrication and characterization of microbial transglutaminase crosslinked gelatin-based scaffolds designed for serving as both cell substrate and growth factor release system. In particular, morphological, biomechanical and biological features have been analyzed. The enzyme ratio applied during the fabrication of the scaffolds affects the swelling capacity and the mechanical properties of the final structure. The developed systems are not cytotoxic according to the biocompatibility tests. The biological performance of selected formulations was studied using L-929 fibroblasts, D1 MSC and MG63 osteoblasts. Moreover, scaffolds allowed efficient osteogenic differentiation and signaling of MSCs. MSC cultured on the scaffolds not only presented lower proliferative and stemness profile, but also increased expression of osteoblast-related genes (Colla1, Runx2, Osx). Furthermore, the in vitro release kinetics of vascular endothelial growth factor (VEGF) and bone morphogenetic protein -2 (BMP-2) from the scaffolds were also investigated. The release of the growth factors produced from the scaffolds followed a first order kinetics. These results highlight that the scaffolds designed and developed in this work may be suitable candidates for bone tissue regeneration purposes.

Keywords: Gelatin, Scaffold, Bone, Tissue Engineering, Drug Delivery 


\section{Introduction}

The bone tissue has a unique property of self-remodeling and regeneration (Hayrapetyan, et al. 2015). However, there are situations in which the capacity for regeneration of the tissue is insufficient and unsatisfactory as a method of healing (Dimitriou, et al. 2011). Nowadays, the "gold standard" strategy for the treatments of these pathologies results from autologous bone grafting. Nevertheless, several complications are associated with this method including donor site morbidity, prolonged periods of hospitalization and rehabilitation and increased risk of deep infections (Jayash, et al. 2017). As a consequence, an immense effort has been made in order to develop novel therapies that could shed light on this challenge. The interdisciplinary field of tissue engineering and regenerative medicine aim to provide potential solution to injured or diseased tissues by developing functional substitutes that maintain, restore or enhance tissue function. This therapeutic arsenal is based mainly on the use of recombinant proteins, cells, and biomaterials (Guan, et al. 2017).

In the case of bone regeneration, development of porous three-dimensional (3D) structures that act as scaffolds to carry and release those therapeutically active agents could be an interesting strategy. The main purpose of the scaffolds will be to replace temporally the function of the biological tissue and promote the formation of the new bone (Roseti, et al. 2017). In this context, some researchers have proposed the combined use of angiogenic and osteogenic factors as a strategy for the promotion of bone healing. The success for the regeneration of bone tissue using vascular endothelial growth factor (VEGF) and bone morphogenetic protein -2 (BMP-2) together depends not only on the appropriate selection of the dose and the release kinetic, but also on the duration of the experimental study proposed in animals (Dou, et al. 2019; Patel, et al. 2008; Subbiah, et al. 2015).

Although many different materials have been investigated for their potential to the fabrication of these structures (Gibbs, et al. 2016), polymers from natural origin have been of 
particular interest as candidates in the development of scaffolds for bone tissue engineering (Kuttappan, et al. 2016). Gelatin is a natural hydrosoluble polymer that is obtained from the hydrolytic process of collagen. Gelatin shows interesting physicochemical and biological properties, make it suitable for its use in biomedicine (Echave, Saenz Del Burgo, et al. 2017). One very useful property of this biomaterial is the possibility of obtaining gelatins with different isoelectric points. Both positively and negatively charged factors can form ionic complexes with gelatin strands (Yamamoto, et al. 2001). In addition, all types of gelatin have shown to be biocompatible (low immunogenic capacity), biodegradable and non-cytotoxic. Moreover, biologically functional amino acid sequences such as arginine-glycine-aspartic acid (RGD) motif are found in its structure, which improves cell adhesion, differentiation, and proliferation (Echave, Sánchez, et al. 2017). Most importantly, the ability of gelatin to form a thermally reversible network in water can provide cross-linked network structure with sufficient mechanical and thermal stability under physiological environment (Gil, et al. 2005).

Recently, we reported biologically active and biomimetic dual gelatin scaffolds crosslinked with genipin (Sanchez, et al. 2017). However, the use of genipin as a crosslinker agent has several limitations including long crosslinking times, structural coloration and unspecific reactivity (Butler, et al. 2003). Scientists are scrambling to develop methods that can quickly, easily and accurately crosslink gelatin strands. One exciting alternative may be the use of specific enzymes that catalyze the covalent union of amino acids present in the material structure (Teixeira, et al. 2012). The enzyme microbial transglutaminase (mTG) catalyzes the production of an isopeptide bond between a glutamine and lysine residues, without the need for calcium as a cofactor (Chen, et al. 2014). Previous studies have reported the use of this enzyme to obtain covalent crosslinking within stable gelatin hydrogels $(\mathrm{M} . \mathrm{Hu}$, et al. 2017; Yang, et al. 2018). 
The primary aim of this study is the design, development and characterization of gelatin scaffolds crosslinked with mTG. Morphology and biomechanical properties have been addressed as well as the biological characteristics of the scaffolds on different cell types. Furthermore, the capacity of retention and release of key growth factors in bone remodeling, such as VEGF and BMP-2 have also been examined in-vitro.

\section{Materials and methods}

\subsection{Materials}

Gelatin from bovine skin Type B with $\approx 225$ bloom strength, Cell Counting Kit-8 (CCK-8) and Collagenase $\mathrm{P}$ were purchased from Sigma-Aldrich (Spain). mTG derived from Streptoverticillium mobaraense with a specific activity of $100 \mathrm{U} / \mathrm{g}$ was kindly supplied by Ajinomoto Foods Europe (France). Mouse L-929 fibroblasts and mouse D1 ORL UVA Mesenchymal Stem Cells (MSCs) cell lines, Dulbecco's Modified Eagle's Medium (DMEM 30-2002), horse serum and Eagle's Minimum Essential Medium (EMEM 30-2003) culture mediums were obtained from ATCC (Spain). MG63 cells were immortalized osteoblasts isolated from a 14 years-old caucasian male osteosarcoma. Trypsin, Hoechst 33342, fetal bovine serum (FBS), Phosphate Buffered Saline (PBS) $\mathrm{pH}=7.4$ (1X) and PenicillinStreptomycin were purchased from Fisher Scientific (Spain). rhVEGF was kindly supplied by Agrenvec (Spain). Finally, VEGF ELISA kit, BMP-2 ELISA kit and rhBMP-2 were obtained from Peprotech (UK).

\subsection{Cell Culture}

The cells used to test the biological performance of the formulations were cultivated with a specific culture medium. Mouse L-929 fibroblasts were cultured in EMEM 30-2003 growth medium supplemented with horse serum $(10 \% \mathrm{v} / \mathrm{v})$ and $1 \%(\mathrm{v} / \mathrm{v})$ penicillin-streptomycin. For the culture of D1 MSCs, the DMEM 30-2002 medium was supplemented with FBS (10\% $\mathrm{v} / \mathrm{v})$ and $1 \%(\mathrm{v} / \mathrm{v})$ penicillin-streptomycin. MG63 osteoblasts were cultured with DMEM 
culture medium supplemented with FBS (5\% v/v), 1\% (v/v) L-Glutamine and gentamicin $(0.5 \% \mathrm{v} / \mathrm{v})$. Primary murine MSC from bone marrow (BM-MSCs) were used to analyze the influence of the scaffolds on the progression in osteogenic differentiation of these cells. The isolation of the cells was achieved from the femurs of 6-8 week old mice, as previously described elsewhere (Aquino-Martinez, et al. 2016; Soleimani and Nadri 2009). Briefly, soft tissues were cleaned and the femurs kept in complete media (DMEM supplemented with 10\% FBS, $1 \%(\mathrm{v} / \mathrm{v})$ penicillin/streptomycin, $1 \mathrm{mM}$ sodium pyruvate and $2 \mathrm{mM}$ L-glutamine). The femur ends were cut and the bone marrow was flushed and collected. Cell suspension was filtered with a $70 \mu \mathrm{m}$ cell strainer (Falcon, USA), transferred to a $100 \mathrm{~mm}$ cell culture plate and incubated at $37^{\circ} \mathrm{C}$. The media was changed after 24 hours and then every eight hours for two to three days to discard non-adherent cells. After five to seven days, when the adherent cells reached $75 \%-80 \%$ of confluence, the cells were washed three times with warmed PBS and trypsinised for three minutes at room temperature. The lifted cells were cultured and expanded in complete media. For osteogenic differentiation, cells were cultured in $\alpha$-MEM containing with 10\% FBS, $1 \%(\mathrm{v} / \mathrm{v})$ penicillin-streptomycin, $2 \mathrm{mM}$ L-glutamine, $1 \mathrm{mM}$ sodium pyruvate with $10 \mathrm{mM} \beta$-glycerophosphate and $50 \mu \mathrm{g} / \mathrm{ml}$ ascorbic acid for 10 days. All cell cultures were kept at $37^{\circ} \mathrm{C}$ in a humidified atmosphere of $95 \%$ air with $5 \% \mathrm{CO}_{2}$. The split of the cells was performed routinely when cells reached confluence.

\subsection{Development of enzymatically crosslinked gelatin-based 3D scaffolds}

Gelatin-based 3D scaffolds were prepared by the enzymatic crosslinking of gelatin with mTG. Briefly, a homogeneous dispersion of gelatin was prepared by dissolving Type B gelatin powder in distilled water at $40^{\circ} \mathrm{C}$ under constant stirring for 45 minutes. Simultaneously, the mTG solution was prepared in deionized water at room temperature (100 $\mathrm{mg} / \mathrm{ml}$ ). Then, the required volume of the enzyme solution was added to the gelatin solution and mixed for another 5 minutes. Nine different formulations were prepared varying the final 
concentration of gelatin $(10,15$ and $20 \% \mathrm{w} / \mathrm{v})$ and the enzymatic activity $(10,20,30 \mathrm{U} / \mathrm{g}$ gelatin) (Fig. 1A). Subsequently, hydrogel solution $(5 \mathrm{ml})$ was casted into $100 \mathrm{~mm}$ Petri dishes and the formulations were kept at $4{ }^{\circ} \mathrm{C}$ for 1 hour in order to get fully crosslinked hydrogels. Afterward, the hydrogels were punched out to obtain $8 \mathrm{~mm}$ diameter 3D scaffolds. These scaffolds were immersed into ethanol $(70 \%(\mathrm{v} / \mathrm{v}))$ for 10 minutes and thereafter they were washed twice in PBS. Finally, the scaffolds were frozen at $-80^{\circ} \mathrm{C}$ and freeze-dried for 42 hours.

\subsection{Swelling behavior and Mechanical properties}

A swelling study was carried out to determine the ability of the scaffolds to absorb and retain water. The swelling ratio was calculated using equation 1; where Ws and Wo are the weight of wet and freeze-dried scaffolds, respectively. First, dry scaffolds were weight prior to immersion into PBS solution. They were maintained at $37^{\circ} \mathrm{C}$ and under constant shaking (300 rpm) for 24 hours. Afterward, the excess surface water of the wet scaffolds was gently removed with a filter paper and then the scaffolds were weighed again. Four different samples were used for each type of scaffold, and the average value was used for further analysis.

\section{Equation 1: $\quad$ Swelling ratio $=(W s-W o) / W o$}

The mechanical properties of enzymatically crosslinked scaffolds were defined with Instron Microtester 5548 equipment with a precision of $0.001 \mathrm{~mm}$ and $0.0001 \mathrm{~N}$ in displacement and force, respectively. Young's modulus was determined by uniaxial unconfined static compression test using eight replicates previously rehydrated with PBS. A protocol described by Acosta Santamaría (Acosta Santamarí-a, et al. 2013) was followed to complete the mechanical properties characterization.

\subsection{Scanning Electron Microscopy (SEM)}


The morphology and microporous structure of the fabricated 3D scaffolds were assessed using SEM. Images of the surface and transverse section of the scaffolds were acquired to assess the structure of the formulations and see the arrangement of the pores throughout them. The dried scaffolds were covered with carbon adhesive tape and they were examined by Hitachi S4800 microscope.

\subsection{Biocompatibility study}

The cytocompatibility of the scaffolds was evaluated by using direct and indirect tests, following the guideline ISO 10993 (Biological evaluation of medical devices guideline: cytotoxicity on extracts and cytotoxicity by direct contact). These assays were performed using L-929 fibroblasts.

To evaluate the toxicity produced by cell-scaffold direct interaction, $3.5 \times 10^{4}$ cells were seeded in a 24 wells plate for 24 hours. Concurrently, dry scaffolds were immersed in $1 \mathrm{ml}$ of complete culture medium for 24 hours, in order to get hydrated samples. Thereafter, direct contact between cells and scaffolds was achieved by placing a hydrated scaffold above each cell-containing wells and they were cultured for 24 hours more.

On the other hand, $5 \times 10^{3}$ fibroblast cells per well were plated in a 96-well cell culture plate to evaluate indirect cytotoxicity of the scaffolds. Simultaneously, freeze-dried scaffolds were immersed into growth medium for 24 hours under continuous shaking in order to get the extracts. After the incubation, cell culture medium of fibroblast cells was replaced by scaffold's extracts and maintain for 24 hours.

In both experiments metabolic activity of the cells was evaluated using the CCK-8 assay, following kit guideline. This assay is based on sensitive colorimetric to determine the number of viable cells in cell proliferation and cytotoxicity assays. The reagent is decreased by mitochondrial dehydrogenases in cells to form an orange-colored product (formazan). The amount of the formazan dye generated by the activity of mitochondrial dehydrogenases in 
cells is directly related to the number of viable cells in culture. For that, absorbance was measured by a microplate reader Tecan Infinite M2000 at $450 \mathrm{~nm}$. The mean absorbance value obtained in the control wells was considered as $100 \%$ cell viability. Cells seeded in control wells were not in contact either with scaffolds directly or with the extracts.

\subsection{Biological performance of $3 D$ scaffolds}

The biological performance of the developed formulations was assessed concurrently with both established cell lines and primary cells. In the cell lines case, L-929 fibroblasts, D1 MSCs and MG63 osteoblastic human origin cells that have been widely used in bone tissue engineering purposes were tested. These cells were seeded on the surface of the scaffolds and at different time intervals $(4,24$ and 72 hours) the cellular metabolic activity determination and nuclei staining was performed in order to analyze the cell density in each sample. Briefly, the scaffolds were exposed to UV light for 10 minutes and $20 \times 10^{3}$ cells/scaffold were seeded. The surface of the polystyrene plate was taken as $2 \mathrm{D}$ control. For the analysis, the culture medium was removed to discard the non-adhered cells and metabolic activity of the remaining cells was analyzed by the CCK- 8 assay following the manufacturer's indications. Besides, cells were fixed in formaldehyde for 10 minutes at room temperature and Hoechst reagent was added at a $10 \mathrm{mg} / \mathrm{ml}$ concentration. Finally, the nuclei were observed using an inverted fluorescence microscope (Nikon TMS). Nuclei counting was carried out using 4x objective and 4 images per scaffold were analyzed using Image $\mathrm{J}$ software.

In addition, primary bone marrow MSC from mice were used to analyze the influence of the scaffolds on the progression in osteogenic differentiation of these cells.

\subsection{Western blot}

Cell lysates from BM-MSCs were resolved on PAGE and transferred to Immobilon-P membranes (Millipore). Primary antibodies toward phosphorylated ERK (Cell Signalling 9102), phosphorylated p38 (Cell Signaling, 9211), phosphorylated S6 (Cell Signaling, 2211) 
and $\beta$-actin (Abcam ab6276) were used at a 1:1000 dilution. Immuno-reactive bands were visualized using horseradish-peroxidase-conjugated secondary antibodies and an EZ-ECL kit (Biological Industries, Cromwell, CT, USA).

\subsection{Gene expression analysis}

Total RNA was extracted from BM-MSCs by TRIsure reagent (Bioline). Two $\mu \mathrm{g}$ of purified RNA was reverse-transcribed by the use of a High-Capacity cDNA Reverse Transcription Kit (Applied Biosystems). Quantitative PCRs were performed on ABI Prism 7900 HT Fast Real-Time PCR System with SensiFAST Probe Hi-ROX Mix (Bioline) and TaqMan 5'-nuclease probe method (Applied Biosystems) to measure Nanog, Oct4 (Pou5f1), Osx (Sp7), Runx2 and Colla1 mRNA expression. All transcripts results were normalized to TATA binding protein $(T b p)$ expression.

\subsection{In vitro Release of Growth Factors}

The release of growth factors assay in-vito test was completed with two relevant molecules that have demonstrated efficacy in generating substitutes for bone regeneration: VEGF (K. Hu and Olsen 2017) and BMP-2 (El Bialy, et al. 2017).

First, $300 \mathrm{ng}$ of VEGF and $1000 \mathrm{ng}$ of BMP-2 were incorporated into the formulations, adding the required volume over the dried scaffolds. They were left incubating at $37^{\circ} \mathrm{C}$ for 12 hours, for the adsorption process. Thereafter, scaffolds were washed with $1 \mathrm{ml}$ PBS under constant shaking in order to remove unbound protein fraction. The encapsulation efficiency (EE) was calculated following the equation 2, where $\mathrm{D}$ is the amount of the protein added and unloaded protein is the amount of the protein detected in the washing sample. Then, $1 \mathrm{ml}$ of PBS was added to the tubes containing scaffolds and the sampling phase was started, taking the samples at different time intervals. The specimens were frozen at $-80^{\circ} \mathrm{C}$, prior to measuring the growth factor concentration. To conclude the study, a solution of $0.5 \mathrm{mg} / \mathrm{ml}$ 
collagenase $\mathrm{P}$ was added to the tubes in order to degrade the scaffolds and quantify the remaining amount of the protein without releasing.

\section{Equation 2: $\quad E E=((D-$ unloaded protein $) / D) * 100$}

During this assay, Protein LoBind Eppendorf tubes were utilizad and there were kept at $37^{\circ} \mathrm{C}$ under orbital shaking at $40 \mathrm{rpm}$. The quantification of growth factors contents in the samples was performed with commercially available Quantikine colorimetric sandwich ELISA kits following the instructions of the manufacturer.

The experimental data obtained from the in vitro release assays were fit to the first-order kinetic mathematical model (equation 3 and 4) using the non-linear regression module of GraphPad Prism software, version 7.0. \% VEGF released and \% BMP-2 $2_{\text {released }}$ values correspond to the release of the cumulative percentage of growth factor at time $t$. $\mathrm{K}$ is the first-order rate constant expressed in hour ${ }^{-1}$ and $\% \mathrm{VEGF}_{\text {released }} \infty$ and $\% \mathrm{BMP}-2_{\text {released }} \infty$ correspond to the maximal percentage of the growth factors released at maximum interval.

Equation 3: $\quad \% V E G F_{\text {released }}=\% V E G F_{\text {released } \infty}\left(1-\exp ^{-K \cdot t}\right)$

Equation 4: $\quad \% B M P-2_{\text {released }}=\% B M P-2_{\text {released }}\left(1-\exp ^{-K \cdot t}\right)$

\subsection{Data analysis and statistics}

Data are presented as mean \pm S.D. (standard deviation) shown by the error bars. Statistical analysis was performed by GraphPad Prism software, version 7.0. Shapiro-Wilk test was used for Normal distribution determination. Statistical analysis was carried out by one-way Analysis of Variance (ANOVA) followed by the Tukey post hoc test for multiple comparisons in normally distributed data. Student's $t$-test was empolyed for differences determination between two groups. In case the data did not fit the normal distribution, the nonparametric Kruskal-Wallis one-way analysis of variance was utilized. Statistical significance between groups was considered at $\mathrm{p}<0.05$.

\section{Results and Discussion}




\subsection{Swelling Behavior and Mechanical Properties}

Nine different enzymatically crosslinked gelatin-based 3D scaffolds were successfully fabricated by freeze-drying technique. Gelatin concentrations extended from 10 to $20 \% \mathrm{w} / \mathrm{V}$ whereas crosslinking proportions ranged between 10 and $30 \mathrm{U} / g$ gelatin. The mTG enzyme catalyzes the isopeptide bonds between the $\gamma$-carboxamide groups of glutamyl residue and the $\varepsilon$-amino groups of the lysine residue (Fig. 1A). Its catalytic activity is independent for the presence of calcium ions, being able to achieve the stable covalent crosslinking of the gelatin fibers in soft conditions during the fabrication of gelatin-based hydrogels for regenerative purposes (Alarake, et al. 2017).

Both dried and rehydrated scaffolds in PBS were weighted in order to calculate the swelling ratio following equation 1 . All the formulations proved to have a great capacity of hydratation during the assay, going from whitish opaque structures to completely transparent systems (Fig. 1B). The swelling ratio was significantly lower in cases in which the enzyme ratio was higher (Fig. 1C). The scaffold with the greatest swelling capacity was composed of $10 \%$ gelatin and $10 \mathrm{U} / \mathrm{g}$ of $\mathrm{mTG}$ showing the ratio of 12.19 . On the other hand, the prototype with the highest concentration of gelatin and enzyme showed the lowest ability to absorb water with the swelling ratio of 6.11 . In fact, the increase of polymer concentration hinders the water penetration into the hydrogel structure. Consequently, our results are in accordance with previous works that have confirmed that more enzymatic activity of mTG turns out to present less ability to retain water (Alarake, et al. 2017).

Inversely, the stiffness of the structures was significantly higher when the concentration of the gelatin and the level of hydrogel crosslinking was increased (Fig. 1D). These results are in accordance with previous work, where the crosslinking grade sets the elasticity of the developed matrix (Engler, et al. 2006). Therefore, the formulations containing $20 \%$ of gelatin and $20 \mathrm{U} / \mathrm{g}$ and $30 \mathrm{U} / \mathrm{g}$ mTG presented Young Modulus values of $38.7 \pm 2.2$ and $41.9 \pm 8.0$ 
respectively. The elasticity values of the developed hydrogels are on a par with osteoid tissue mechanical characteristics (Zaky, et al. 2017). In fact, this tissue is a non-mineralized transient structure which is produced first during bone tissue formation prior to been replaced by the mineralized secondary bone (Lopes, et al. 2018) .

\subsection{Biocompatibility Study}

In the biocompatibility studies, $100 \%$ of the viability was considered the absorbance value obtained in the CCK-8 assay with the control samples that were not in direct contact with the scaffolds or the extracts.

In the cytotoxicity assay on extracts, all scaffolds achieved cell viability greater than $100 \%$. In contrast, all the scaffolds showed lower levels of viability in the toxicity study by direct contact between cells and scaffolds (Fig. 1E). This effect may be due to the presence of RGD sequences in the surface of the scaffolds, since these integrin-binding domains are present in the innate structure of the gelatin (Yue, et al. 2015). Focal adhesions between the cells and the gelatin fibers are produced by the binding of integrins present in the cellular cytoplasmic membrane with those sequences mentioned above (LeBaron and Athanasiou 2000). Such an effect in gelatin-based structures has been previously described. Even so, in all cases the L929 fibroblasts viability was above 70\%, the limit required by ISO guidelines to consider as non-cytotoxic for in vitro tests. Besides, the increase of the enzyme activity during the preparation of the systems does not come from a significant decrease in cell viability.

\subsection{Morphological Analysis}

Based on the results obtained in the swelling, stiffness determination and biocompatibility studies, two prototypes were selected for further in vitro characterization: $10 \%$ gelatin +20 $\mathrm{U} / \mathrm{g}\left(\mathrm{GEL} \_10 / 20\right)$ and $20 \%$ gelatin $+20 \mathrm{U} / \mathrm{g}$ (GEL_20/20). Even though the cytocompatibility values for both formulations were similar, significant differences were 
determined in relation to their stiffness and ability to swell. Indeed, GEL_10/20 formulation presented higher capability to absorb water while GEL_20/20 was twice stiffer.

The images obtained by SEM revealed random conformation of gelatin fiber densely packed with the presence of pores distributed throughout all surface that allowed the rehydration. In this study, 3D scaffolds with different concentrations of gelatin and the enzyme mTG have been fabricated by freeze-drying technique. This fabrication method is a useful procedure to create pores in the structure (Garg and Goyal 2014). In fact, in the course of the preparation process, ice crystals are formed in the scaffold during the freezing phase allowing the creation of pores by the sublimation and desorption (Mano, et al. 2007). Descriptive images of the surface and the cross-section of the formulations are represented in Fig. 1F. In fact, a sponge-like isotropic structure with deep pores that crossed the transversal section was obtained. In both cases, the pore size was measured in the range of $150-230 \mu \mathrm{m}$ and no differences in the distribution of the pores was revealed in the microstructural analysis.

\subsection{Culture of Cells onto 3D Scaffolds}

Cell-scaffold interactions were evaluated using L-929 fibroblasts, D1 MSCs and MG63 osteoblasts. In the case of fibroblasts, the number of cells adhered at 4 hours in the three conditions was similar, without significant differences in metabolic activity. At 24 and 72 hours, the number and the activity of the cells in the control and the GEL_10/20 scaffold was similar, with a slight decrease in the case of GEL_20/20 (Fig. 2A-B). Regarding the interaction between scaffolds and D1 MSCs no differences were found between the control and the two type scaffolds at 4 and 24 hours. However, a slight decrease in the case of GEL_20/20 was observed in the value obtained in the CCK-8 assay at 72 hours (Fig. 2D). The distribution of the cell nuclei on the scaffolds remained homogeneous throughout the entire surface (Fig. 2C). Finally, in the case of the study with MG63 osteoblasts, differences 
between the control and the two types of scaffolds were observed from 4 hours post-seeding. The adhesion of osteoblast was lower in both cases compared with the control, as could be seen in the images of the nuclei stains (Fig. 2E). The values of the optical densities obtained in the CCK-8 assay (Fig. 2F) corroborate these qualitative results.

Since both the metabolic activity and the number of adhered cells to the scaffolds have been increased during the incubation period for all the cell lines studied, it can be concluded that the developed 3D polymeric scaffolds are suitable structures to support cell growth on them.

\subsection{5 Culture of BM-MSCs in the scaffolds increases the expression of osteogenic} genes

We also examined the ability of these scaffolds to either stimulate osteogenesis or maintain the undifferentiated status of the BM-MSCs. Therefore, we cultured the cells in the scaffolds for 10 days. The gene expression quantification of the stemness markers Oct4 and Nanog demonstrate that, after 10 days culture in the GEL 10/10 and GEL 20/20 scaffolds, the expression of Oct4 and Nanog was reduced (Fig. 3A). A parallel analysis of osteoblastic gene expression showed that the Collal, Runx2 and Osx mRNA levels were significantly increased after 10 days (Fig. 3A). The addition of BMP-2 during the differentiation induced a further increase in the expression of these markers, more evident for cells cultured in the $10 / 20$ scaffold.

To determine the mechanisms of BM-MSCs differentiation in the scaffolds, we analyzed intracellular signaling triggered by the cell culture in the different scaffolds. Analysis was performed after 10 days of differentiation of BM-MSCs in the scaffolds. The levels of phosphorylated ERK1/2 were decreased after 10 days suggesting a lower proliferative rate of the cells at these time points. In return, S6-kinase and p38 signaling pathways were activated after 10 days. Since activation of p38 and S6-kinase are required for osteogenic 
differentiation, these results suggest increased osteogenic differentiation ability of BM-MSCs when cultured in the GEL 10/20 and GEL 20/20 scaffolds (Fig. 3B). Therefore, BM-MSCs, cultured in the GEL 10/10 and GEL 20/20 scaffolds, have the ability to reduce their stemness and proliferation and promote their specification into an osteogenic program.

\subsection{In vitro Release of Growth Factors}

An angiogenic growth factor, VEGF, and BMP-2 as a potent osteoinductive factor were chosen for the in vitro release studies from GEL_10/20 and GEL_20/20 scaffolds. Successful bone healing relies on several biological processes that act in a controlled spatiotemporal manner. These include inflammation, soft callus formation, cartilage turnover and bone remodeling (Marsell and Einhorn 2011). The VEGF protein is present in almost all the phases of bone repair (K. Hu and Olsen 2017). In fact, VEGF increases the permeability of sinusoidal endothelial cells and induces neutrophil migration during the inflammation phase (Ancelin, et al. 2004). This growth factor has been shown to be effective in the process of differentiation of periosteal progenitor cells to osteoblasts ( $\mathrm{K}$. $\mathrm{Hu}$ and Olsen 2016). Meanwhile, the BMP-2 is a potent inducer of bone and cartilage formation. It has been reported that BMPs can activate pathways that stimulate VEGF synthesis (Ai-Aql, et al. 2008). demonstrating that there is a close relationship between both growth factors during the healing process of the bone. BMP-2 is currently the most commonly used cytokine as bone graft substitutes (McKay, et al. 2007) and rhBMP-2 containing lyophilized product is on the market as an alternative treatment for bone grafting for several clinical conditions (El Bialy, et al. 2017). Therefore, it seems an interesting strategy to use these growth factors synergistically to develop treatments for bone regeneration (Aksel and Huang 2017; An, et al. 2017). However, the spatiotemporal control over growth factor release, which is necessary to achieve physiological doses in the injured tissue (Anitua, et al. 2008), remains a considerable challenge by now. 
In the case of VEGF, both scaffolds showed high EE, 91.4\% and 92.5\% for GEL_10/20 and GEL_20/20, respectively. In the case of the GEL_10/20 scaffold, an $85.4 \%$ of the absorbed protein (233.6 ng) was released during the test period. A burst effect of 59.5\% during the first 24 hours was observed in the release curve of GEL_10/20 matrices. Then, during the following days of the study, a total of $70.7 \mathrm{ng}$ of VEGF released from the scaffolds were detected. In contrast, the GEL_20/20 scaffold released only $61.1 \%$ of total encapsulated VEGF (169.7 ng) until the end of the assay, being the burst effect in the first 24 hours similar (51.4\%) (Fig. 4A-B).

The release profiles of both groups have been fitted to the first-order mathematical model following the equation. 3. As can be seen in Fig. 4C the correlation for the model is appropriate, being the regression coefficients $\left(R^{2}\right) 0.9496$ and 0.9352 for the systems GEL_10/20 and GEL_20/20, respectively. Fitting parameters can be found in the table of Fig. 4D.

Regarding the release of BMP-2, both types of scaffolds presented similar EE over $89 \%$. GEL_10/20 released 614.6 ng of BMP-2 during all the kinetic period, while the prototype GEL_20/20 accumulated $443.7 \mathrm{ng}$ released (Fig. 5B). In the case of GEL_10/20 an initial burst effect of $56.5 \%$ was observed during the first 24 hours. After that, additional $112.0 \mathrm{ng}$ of BMP-2 were released from the scaffolds until the end of the assay. Otherwise, GEL_20/20 scaffold presented an initial burst effect of $43.2 \%$ during the first 24 hours and then, a total of $57.5 \mathrm{ng}$ of the growth factor was detected over the next days (Fig. 5A-B). The adjustment of the BMP-2 release kinetic following the equation 4 revealed a good correlation with the model, presenting values of 0.9610 and 0.9723 for $\mathrm{R}^{2}$ (Fig. 5C). The kinetic parameters are summarized in Fig. 5D.

In both growth factors kinetics, the significant differences in the release of the therapeutic agents are accentuated in the second phase of the liberation process, after the burst effect. In 
fact, the formulation GEL_20/20 presents greater capacity for retention of the factor. The total amounts released from these formulations are lower. The electrostatic bonding between gelatin and a wide range of bioactive molecules by the union of opposite charges has been largely used as a strategy to use this biomaterial as a drug delivery carrier. Different types of systems such as nanoparticles, microparticles or 3D scaffolds have been developed so far (Foox and Zilberman 2015). The gelatin used for the production of 3D systems in this work has an isoelectric point of 4.7-5.2. On the other hand, the isoelectric point of both BMP-2 and VEGF is higher (8.5 and 7.6 respectively). Thus, an ionic complexation between the matrix and the factors is expected to arise at physiologic $\mathrm{pH}$. Since the GEL_20/20 is prepared with more amount of gelatin, more interactions between negatively charged aminoacids and these growth factors are expected.

In this system, the release of the factors from the $3 \mathrm{D}$ gelatin scaffolds follows the firstorder kinetics. The first-order mathematical model can be used to describe the dissolution of drugs in pharmaceutical dosage forms such as porous matrices containing water-soluble drugs (Dash, et al. 2010). In this kinetic model the release is proportional to the quantity of drug remaining in the dosage form. Release from these systems depends on the drug concentration, since the rate of the process rises linearly with an increase in drug concentration. In the in vitro release study carried out in this work, the cumulative percentage released in all cases corresponds to the parameter estimated in the non-linear regression $(\%$ $\mathrm{VEGF}_{\text {released } \infty}$ and $\% \mathrm{BMP}-2_{\text {released }} \infty$ ). With these results, we can conclude that complete release of the factors by diffusion has happened during the time of the assay. It is envisaged that the rest of the unreleased protein will be released by the degradation of the scaffold under real physiological conditions (Yamamoto, et al. 2001). Actually, gelatin is considered as biodegradable material since, sensitive moieties to matrix metalloproteinases, the enzymes that remodel de extracellular matrix, are maintained in its structure (Cui, et al. 2017). 
Additionally, we have observed that the total amount of all the collected samples does not fully coincide with the theoretical loaded dose. The difference in both proteins has been greater in the scaffolds GEL_20/20 (Fig. 4A and Fig. 5A). This could be due to the incorporation of collagenase at the end of the study to degrade the scaffold and quantify the remaining protein not released. It is well-known that collagenase is a protease that cleaves peptide bonds and therefore the structures of growth factors may be affected (Visse and Nagase 2003). In the GEL_20/20 scaffolds less amount of protein has been released during the assay and consequently the remaining fraction is expected to be higher. To ensure this effect, we have quantified the concentration of VEGF in PBS in the absence or presence of the same concentration of collagenase used in the in vitro release test. The results demonstrated that there is a significant decrease in the protein amount in the presence of this protease (Fig. S1).

The prototypes that have been developed in this work could be considered versatile release systems, since they present the potential to serve as a support for the release of various growth factors. However, the release profile is dependent on the ionic interaction with gelatin. For this reason, the release profile of both growth factors has been similar, delivering approximately half of the dose in the first 24 hours. The process of regeneration of the bone tissue is considered a set of events controlled spatio-temporally by the action of many growth factors. For this reason, it could be immensely interesting to incorporate new design strategies to our systems to achieve the release of BMP-2 delayed over time, to better mimick the natural healing environment. The inclusion of osteoinductive growth factors inside of particulate systems of both micro and nano scale might help on tuning the release profile of such agents (Kim, et al. 2017).

\section{Conclusions}


In this experimental work, nine different 3D scaffolds using gelatin from bovine skin crosslinked with different ratios of mTG by freeze-drying technique, have been designed, produced and characterized. Porous structures have been obtained with a higher degree of swelling when the proportion of the enzyme was lower. The structures presented similar elasticity values of osteoid tissue. In all the prototypes absence of cytotoxicity was obtained. Two candidates were chosen to further study the cellular interaction, and capacity of retention and release of growth factors. The stemness and proliferative capacity of the mesenchymal stem cells cultured on the scaffolds was reduced while the expression of osteoblast-related genes (Colla1, Runx2, Osx) was potentiated. The selected prototypes were able to retain and release VEGF and BMP-2, following a first-order release kinetic. Our preliminary in vitro results suggest that gelatin-based 3D dual scaffolds could be useful for future in vivo bone regenerative purposes.

\section{Declarations of interest}

None.

\section{Acknowledgements}

Authors wish to thank the Spanish Ministry of Economy, Industry and Competitiveness (SAF2016-76150-R and BFU2017-82421-P) and technical assistance from the ICTS NANBIOSIS (Drug Formulation Unit, U10) at the University of the Basque Country. We also appreciate the support from the Basque Country Government (Grupos Consolidados, No ref: IT907-16). The authors wish to acknowledge the support from Agrenvec, Madrid. Echave MC thanks to the Basque Government for the $\mathrm{PhD}$ grant.

\section{References}


Acosta Santamaría, V.A., García Aznar, J.M., Ochoa, I., Doblare, M., 2013. Effect of sample pre-contact on the experimental evaluation of cartilage mechanical properties. Exp. Mech., 53, 911-917. doi: 10.1007/s11340-012-9698-x.

Ai-Aql, Z.S., Alagl, A.S., Graves, D.T., Gerstenfeld, L.C., Einhorn, T.A., 2008. Molecular mechanisms controlling bone formation during fracture healing and distraction osteogenesis. J. Dent. Res., 87, 107-118. doi: 10.1177/154405910808700215.

Aksel, H., Huang, G.T., 2017. Combined Effects of Vascular Endothelial Growth Factor and Bone Morphogenetic Protein 2 on Odonto/Osteogenic Differentiation of Human Dental Pulp Stem Cells In Vitro. J. Endod., 43, 930-935. doi: 10.1016/j.joen.2017.01.036.

Alarake, N.Z., Frohberg, P., Groth, T., Pietzsch, M., 2017. Mechanical properties and biocompatibility of in situ enzymatically cross-linked gelatin hydrogels. Int. J. Artif. Organs, 40, 159-168. doi: 10.5301/ijao.5000553.

An, G., Zhang, W.B., Ma, D.K., Lu, B., Wei, G.J., Guang, Y., Ru, C.H., Wang, Y.S., 2017. Influence of VEGF/BMP-2 on the proliferation and osteogenetic differentiation of rat bone mesenchymal stem cells on PLGA/gelatin composite scaffold. Eur. Rev. Med. Pharmacol. Sci., 21, 2316-2328.

Ancelin, M., Chollet-Martin, S., Herve, M.A., Legrand, C., El Benna, J., Perrot-Applanat, M., 2004. Vascular endothelial growth factor VEGF189 induces human neutrophil chemotaxis in extravascular tissue via an autocrine amplification mechanism. Lab. Invest., 84, 502-512. doi: 10.1038/labinvest.3700053.

Anitua, E., Sanchez, M., Orive, G., Andia, I., 2008. Delivering growth factors for therapeutics. Trends Pharmacol. Sci., 29, 37-41. doi: 10.1016/j.tips.2007.10.010.

Aquino-Martinez, R., Rodriguez-Carballo, E., Gamez, B., Artigas, N., Carvalho-Lobato, P., Manzanares-Cespedes, M.C., Rosa, J.L., Ventura, F., 2016. Mesenchymal Stem Cells Within Gelatin/CaSO4 Scaffolds Treated Ex Vivo with Low Doses of BMP-2 and Wnt3a Increase Bone Regeneration. Tissue Eng. Part A., 22, 41-52. doi: 10.1089/ten.TEA.2015.0181.

Butler, M.F., Ng, Y., Pudney, P.D.A., 2003. Mechanism and kinetics of the crosslinking reaction between biopolymers containing primary amine groups and genipin. J Polym Sci A Polym Chem, 41, 3941-3953. doi: 10.1002/pola.10960.

Chen, P.Y., Yang, K.C., Wu, C.C., Yu, J.H., Lin, F.H., Sun, J.S., 2014. Fabrication of large perfusable macroporous cell-laden hydrogel scaffolds using microbial transglutaminase. Acta Biomater., 10, 912-920. doi: 10.1016/j.actbio.2013.11.009.

Cui, N., Hu, M., Khalil, R.A., 2017. Biochemical and Biological Attributes of Matrix Metalloproteinases. Prog. Mol. Biol. Transl. Sci., 147, 1-73. doi: 10.1016/bs.pmbts.2017.02.005.

Dash, S., Murthy, P.N., Nath, L., Chowdhury, P., 2010. Kinetic modeling on drug release from controlled drug delivery systems. Acta Pol. Pharm., 67, 217-223. 
Dimitriou, R., Jones, E., McGonagle, D., Giannoudis, P.V., 2011. Bone regeneration: current concepts and future directions. BMC Med., 9. doi: 10.1186/1741-7015-9-66.

Dou, D.D., Zhou, G., Liu, H.W., Zhang, J., Liu, M.L., Xiao, X.F., Fei, J.J., Guan, X.L., Fan, Y.B., 2019. Sequential releasing of VEGF and BMP-2 in hydroxyapatite collagen scaffolds for bone tissue engineering: Design and characterization. Int. J. Biol. Macromol., 123, 622628. doi: 10.1016/j.ijbiomac.2018.11.099.

Echave, M.C., Saenz Del Burgo, L., Pedraz, J.L., Orive, G., 2017. Gelatin as Biomaterial for Tissue Engineering. Curr. Pharm. Des., 23, 3567-3584. doi: $10.2174 / 0929867324666170511123101$.

Echave, M.C., Sánchez, P., Pedraz, J.L., Orive, G., 2017. Progress of gelatin-based 3D approaches for bone regeneration. Journal of Drug Delivery Science and Technology, 42, 6374. doi: 10.1016/j.jddst.2017.04.012.

El Bialy, I., Jiskoot, W., Reza Nejadnik, M., 2017. Formulation, Delivery and Stability of Bone Morphogenetic Proteins for Effective Bone Regeneration. Pharm. Res., 34, 1152-1170. doi: 10.1007/s11095-017-2147-x.

Engler, A.J., Sen, S., Sweeney, H.L., Discher, D.E., 2006. Matrix elasticity directs stem cell lineage specification. Cell, 126, 677-689. doi: 10.1016/j.cell.2006.06.044.

Foox, M., Zilberman, M., 2015. Drug delivery from gelatin-based systems. Expert Opin. Drug Deliv., 12, 1547-1563. doi: 10.1517/17425247.2015.1037272.

Garg, T., Goyal, A.K., 2014. Biomaterial-based scaffolds--current status and future directions. Expert Opin. Drug Deliv., 11, 767-789. doi: 10.1517/17425247.2014.891014.

Gibbs, D.M., Black, C.R., Dawson, J.I., Oreffo, R.O., 2016. A review of hydrogel use in fracture healing and bone regeneration. J. Tissue Eng. Regen. Med., 10, 187-198. doi: 10.1002/term.1968.

Gil, E.S., Spontak, R.J., Hudson, S.M., 2005. Effect of beta-sheet crystals on the thermal and rheological behavior of protein-based hydrogels derived from gelatin and silk fibroin.

Macromol. Biosci., 5, 702-709. doi: 10.1002/mabi.200500076.

Guan, X., Avci-Adali, M., Alarcin, E., Cheng, H., Kashaf, S.S., Li, Y., Chawla, A., Jang, H.L., Khademhosseini, A., 2017. Development of hydrogels for regenerative engineering. Biotechnol. J., 12. doi: 10.1002/biot.201600394.

Hayrapetyan, A., Jansen, J.A., van den Beucken, J.J., 2015. Signaling pathways involved in osteogenesis and their application for bone regenerative medicine. Tissue Eng. Part B. Rev., 21, 75-87. doi: 10.1089/ten.TEB.2014.0119.

Hu, K., Olsen, B.R., 2017. Vascular endothelial growth factor control mechanisms in skeletal growth and repair. Dev. Dyn., 246, 227-234. doi: 10.1002/dvdy.24463.

$\mathrm{Hu}, \mathrm{K}$. , Olsen, B.R., 2016. Osteoblast-derived VEGF regulates osteoblast differentiation and bone formation during bone repair. J. Clin. Invest., 126, 509-526. doi: 10.1172/JCI82585. 
Hu, M., Azeloglu, E.U., Ron, A., Tran-Ba, K.H., Calizo, R.C., Tavassoly, I., Bhattacharya, S., Jayaraman, G., Chen, Y., Rabinovich, V., Iyengar, R., Hone, J.C., He, J.C., Kaufman, L.J., 2017. A biomimetic gelatin-based platform elicits a pro-differentiation effect on podocytes through mechanotransduction. Sci. Rep., 7, 43934. doi: 10.1038/srep43934.

Jayash, S.N., Hashim, N.M., Misran, M., Baharuddin, N.A., 2017. Local application of osteoprotegerin-chitosan gel in critical-sized defects in a rabbit model. PeerJ, 5. doi: 10.7717/peerj.3513.

Kim, H.D., Amirthalingam, S., Kim, S.L., Lee, S.S., Rangasamy, J., Hwang, N.S., 2017. Biomimetic Materials and Fabrication Approaches for Bone Tissue Engineering. Adv. Healthc. Mater., 6, 10.1002/adhm.201700612. Epub 2017 Nov 24. doi: 10.1002/adhm.201700612.

Kuttappan, S., Mathew, D., Nair, M.B., 2016. Biomimetic composite scaffolds containing bioceramics and collagen/gelatin for bone tissue engineering - A mini review. Int. J. Biol. Macromol., 93, 1390-1401. doi: 10.1016/j.ijbiomac.2016.06.043.

LeBaron, R.G., Athanasiou, K.A., 2000. Extracellular matrix cell adhesion peptides: functional applications in orthopedic materials. Tissue Eng., 6, 85-103. doi: $10.1089 / 107632700320720$.

Lopes, D., Martins-Cruz, C., Oliveira, M.B., Mano, J.F., 2018. Bone physiology as inspiration for tissue regenerative therapies. Biomaterials, 185, 240-275. doi: 10.1016/j.biomaterials.2018.09.028.

Mano, J.F., Silva, G.A., Azevedo, H.S., Malafaya, P.B., Sousa, R.A., Silva, S.S., Boesel, L.F., Oliveira, J.M., Santos, T.C., Marques, A.P., Neves, N.M., Reis, R.L., 2007. Natural origin biodegradable systems in tissue engineering and regenerative medicine: present status and some moving trends. J. R. Soc. Interface, 4, 999-1030. doi: 10.1098/rsif.2007.0220.

Marsell, R., Einhorn, T.A., 2011. The biology of fracture healing. Injury, 42, 551-555. doi: 10.1016/j.injury.2011.03.031.

McKay, W.F., Peckham, S.M., Badura, J.M., 2007. A comprehensive clinical review of recombinant human bone morphogenetic protein-2 (INFUSE Bone Graft). Int. Orthop., 31, 729-734. doi: 10.1007/s00264-007-0418-6.

Patel, Z.S., Young, S., Tabata, Y., Jansen, J.A., Wong, M.E., Mikos, A.G., 2008. Dual delivery of an angiogenic and an osteogenic growth factor for bone regeneration in a critical size defect model. Bone, 43, 931-940. doi: 10.1016/j.bone.2008.06.019.

Roseti, L., Parisi, V., Petretta, M., Cavallo, C., Desando, G., Bartolotti, I., Grigolo, B., 2017. Scaffolds for Bone Tissue Engineering: State of the art and new perspectives. Mater. Sci. Eng. C. Mater. Biol. Appl., 78, 1246-1262. doi: 10.1016/j.msec.2017.05.017.

Sanchez, P., Pedraz, J.L., Orive, G., 2017. Biologically active and biomimetic dual gelatin scaffolds for tissue engineering. Int. J. Biol. Macromol., 98, 486-494. doi:

10.1016/j.ijbiomac.2016.12.092. 
Soleimani, M., Nadri, S., 2009. A protocol for isolation and culture of mesenchymal stem cells from mouse bone marrow. Nat. Protoc., 4, 102-106. doi: 10.1038/nprot.2008.221.

Subbiah, R., Hwang, M.P., Van, S.Y., Do, S.H., Park, H., Lee, K., Kim, S.H., Yun, K., Park, K., 2015. Osteogenic/angiogenic dual growth factor delivery microcapsules for regeneration of vascularized bone tissue. Adv. Healthc. Mater., 4, 1982-1992. doi: 10.1002/adhm.201500341.

Teixeira, L.S., Feijen, J., van Blitterswijk, C.A., Dijkstra, P.J., Karperien, M., 2012. Enzymecatalyzed crosslinkable hydrogels: emerging strategies for tissue engineering. Biomaterials, 33, 1281-1290. doi: 10.1016/j.biomaterials.2011.10.067.

Visse, R., Nagase, H., 2003. Matrix metalloproteinases and tissue inhibitors of metalloproteinases: structure, function, and biochemistry. Circ. Res., 92, 827-839. doi: 10.1161/01.RES.0000070112.80711.3D.

Yamamoto, M., Ikada, Y., Tabata, Y., 2001. Controlled release of growth factors based on biodegradation of gelatin hydrogel. J. Biomater. Sci. Polym. Ed., 12, 77-88. doi: $10.1163 / 156856201744461$.

Yang, G., Xiao, Z., Long, H., Ma, K., Zhang, J., Ren, X., Zhang, J., 2018. Assessment of the characteristics and biocompatibility of gelatin sponge scaffolds prepared by various crosslinking methods. Sci. Rep., 8, 1616-018-20006-y. doi: 10.1038/s41598-018-20006-y.

Yue, K., Trujillo-de Santiago, G., Alvarez, M.M., Tamayol, A., Annabi, N., Khademhosseini, A., 2015. Synthesis, properties, and biomedical applications of gelatin methacryloyl (GelMA) hydrogels. Biomaterials, 73, 254-271. doi: 10.1016/j.biomaterials.2015.08.045.

Zaky, S.H., Lee, K.W., Gao, J., Jensen, A., Verdelis, K., Wang, Y., Almarza, A.J., Sfeir, C., 2017. Poly (glycerol sebacate) elastomer supports bone regeneration by its mechanical properties being closer to osteoid tissue rather than to mature bone. Acta Biomater., 54, 95106. doi: 10.1016/j.actbio.2017.01.053.

\section{Figures legends}

Fig. 1: Characterization of enzymatically crosslinked gelatin-based 3D scaffolds. A)

Schematic image of the developed formulations, Gelatin fibers are represented as amino acids chains and the covalent isopeptidic bond formed during the enzymatic crosslinking process is also depicted. B) Digital photography of both lyophilized and rehydrated 3D scaffolds. C) Swelling behavior of the systems displayed on combinatorial heat-diagram. D) Young moduli of the formulations for mechanical analysis. C) Cellular viabilities on direct contact and extracts cytotoxicity tests. F) Representative SEM images of the surface and cross-section of freeze-dried scaffolds. Statistical significance: ${ }^{*} \mathrm{p}<0.05, * * \mathrm{p}<0.01, * * * \mathrm{p}<0.001$ compared to 
the groups with the same concentration of gelatin and ${ }^{\#} \mathrm{p}<0.05,{ }^{\#} \mathrm{p}<0.01,{ }^{\# \#} \mathrm{p}<0.001$ compared to the group with the same enzymatic activity and $10 \%$ of gelatin concentration.

Fig. 2. Biological performance of scaffolds with stablished cell lines. The mitochondrial activity of the cells seeded onto the scaffolds was determined from CCK- 8 assay. The staining of the nuclei was performed at the same time intervals and the quantification from the fluorescence imaging were afterward plotted in heat-diagrams. A and B correspond to the experiments with L-929 fibroblasts. C and D present the data obtained in studies with D1 MSCs. Finally, E and F show the results corresponding to studies with MG63 osteoblasts. Statistical significance: $* \mathrm{p}<0.05, * * \mathrm{p}<0.01, * * * \mathrm{p}<0.001$

Fig. 3: Scaffolds increase osteogenic marker expression. (A) Primary BM-MSCs were cultured on GEL 10/10 or GEL 20/20 scaffolds with or without 2 nM of BMP-2 for 10 days. The mRNA expression of Nanog, Oct4, Colla1, Runx2 and Osterix was analysed and normalised to Tbp levels. (B) Western blot analysis of the phosphorylation levels of ERK, S6 and p38. Cells were cultured in the scaffolds for 10 days. Data was quantified relative to the levels of $b$-actin. Differences were considered significant at $p$ values: $* p<0.05, * * p<0.01$, and $* * * \mathrm{p}<0.001$ when compared to control cells at time 0 .

Fig. 4. In vitro release of Vascular Endothelial Growth Factor (VEGF). A) VEGF amount released at different time points, protein amount detected into the scaffolds at the end of the assay and the total protein detected during the study. B) The cumulative release of VEGF from the two prototype scaffolds analyzed. C) Adjustment of the VEGF release curve according to the first-order release kinetics equation 3 of the GEL_10/20 scaffold and the GEL_20/20 scaffold. D) Regressed parameters for the first-order kinetic model in VEGF release assay. Statistical significance between groups: $* \mathrm{p}<0.05, * * \mathrm{p}<0.01, * * * \mathrm{p}<0.001$. K First-order rate constant, CI - Confidence interval, $\mathrm{R}^{2}$ - Regression coefficient. 
Fig. 5. In vitro release of Bone Morphogenetic Protein - 2 (BMP-2). A) BMP-2 amount released at different time points, protein amount detected into the scaffolds at the end of the assay and the total protein detected during the study. B) The cumulative release of BMP-2 from the two prototype scaffolds analyzed. C) Adjustment of the BMP-2 release curve according to the first-order release kinetics equation 4 of the GEL_10/20 scaffold and the GEL_20/20 scaffold. D) Fitting parameters for the first-order kinetic model in BMP-2 release assay. Statistical significance between groups: $* \mathrm{p}<0.05, * * \mathrm{p}<0.01, * * * \mathrm{p}<0.001 . \mathrm{K}-$ Firstorder rate constant, $\mathrm{CI}$ - Confidence interval, $\mathrm{R}^{2}$ - Regression coefficient. 
A

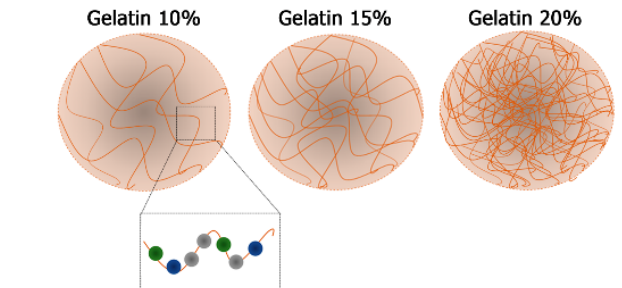

Lysine residue of gelatin

B

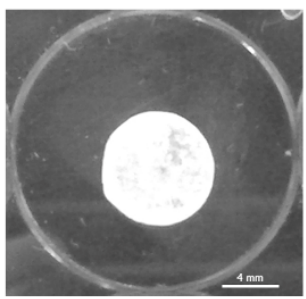
$\mathrm{O}^{\mathrm{C}} \mathrm{NH}_{2}$

Glutamic residue of gelatin

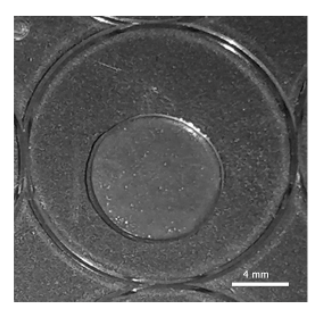

D
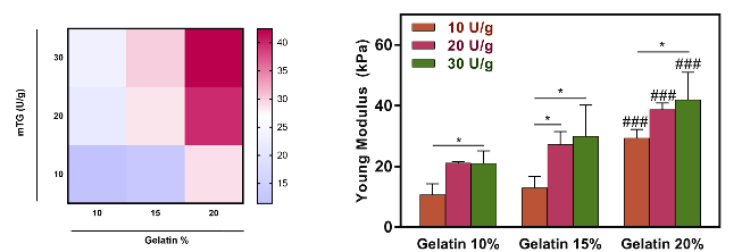

E
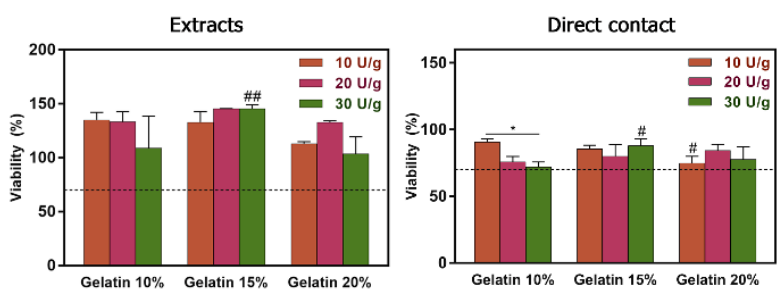

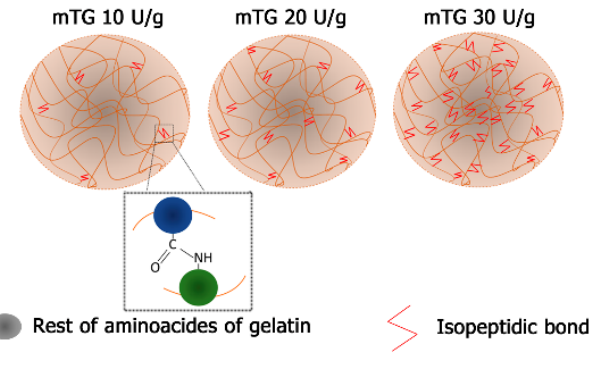

C
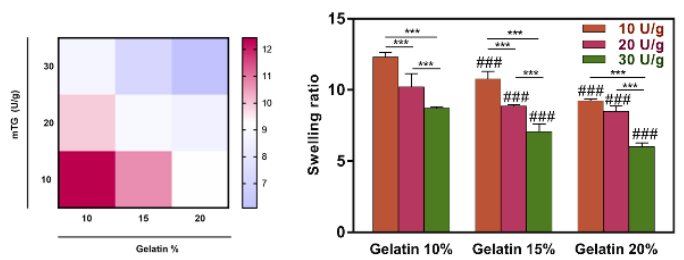

$\mathrm{F}$
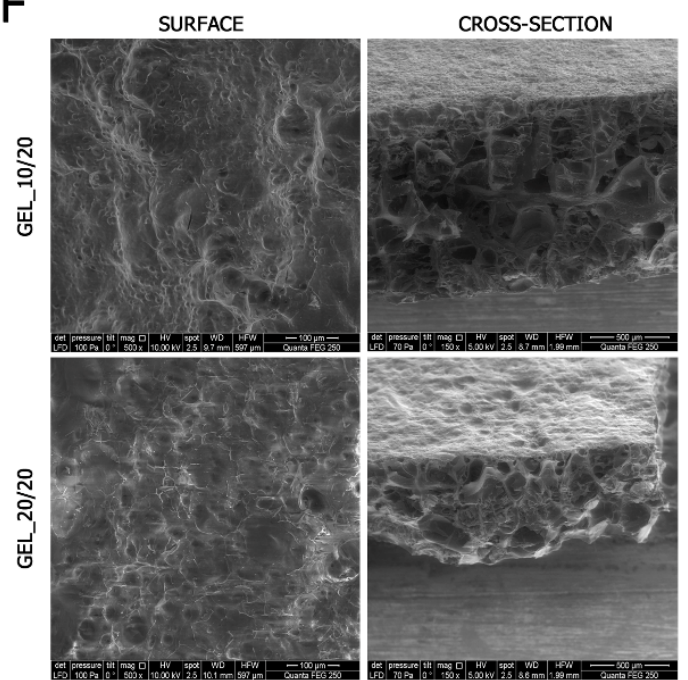
A

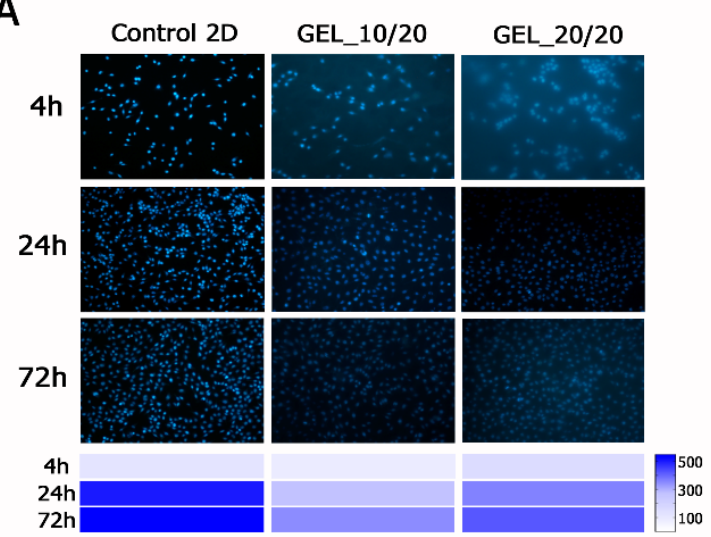

C

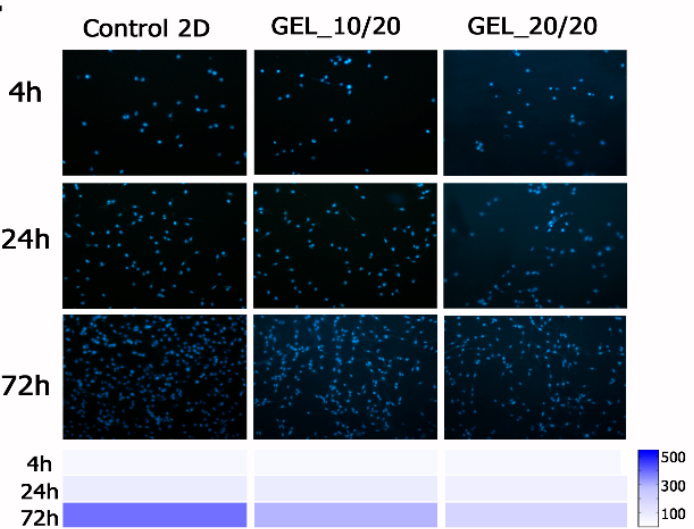

E

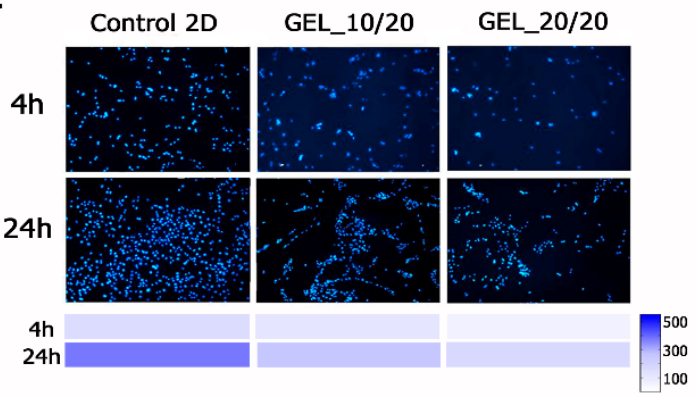

B

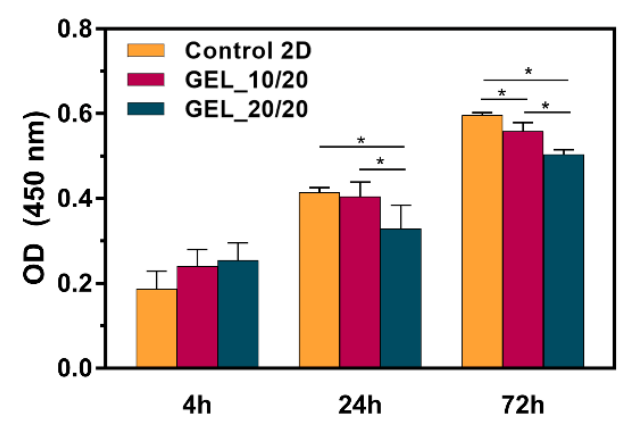

D

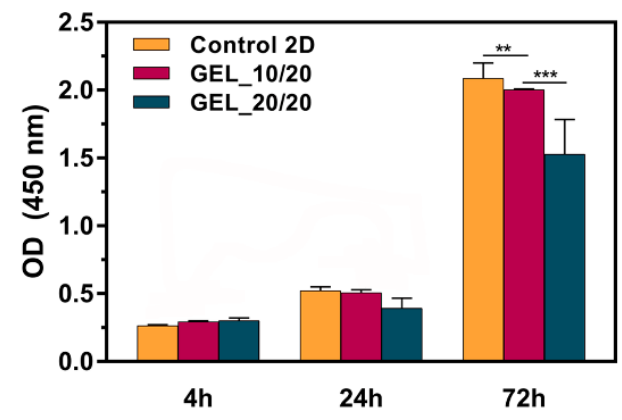

$\mathbf{F}$

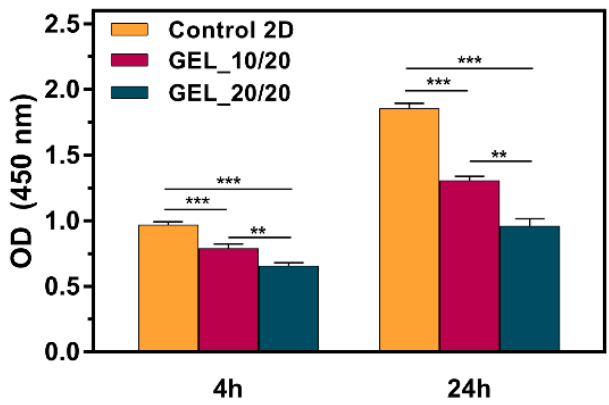



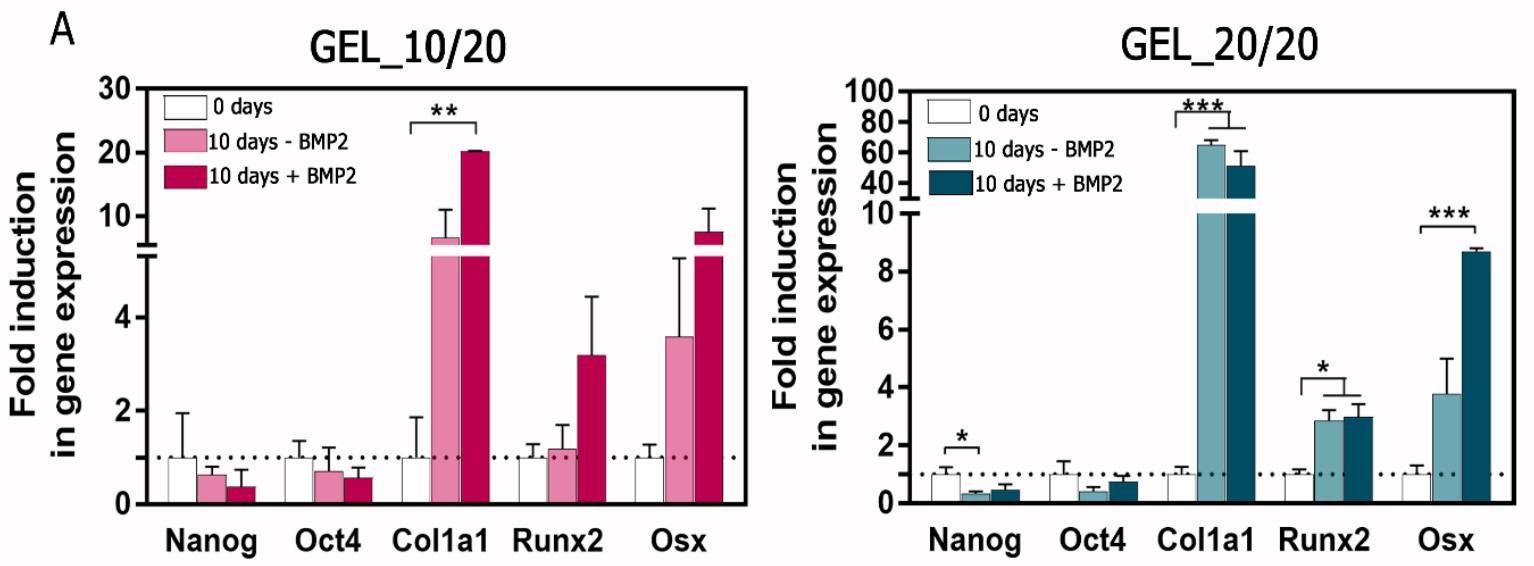

B

$$
\frac{\text { GEL_10/20 }}{0 \quad 10} \frac{}{0} \frac{\text { GEL_20/20 }}{0} \text { days }
$$

pERK

pS6

pp38

b-actin 
A

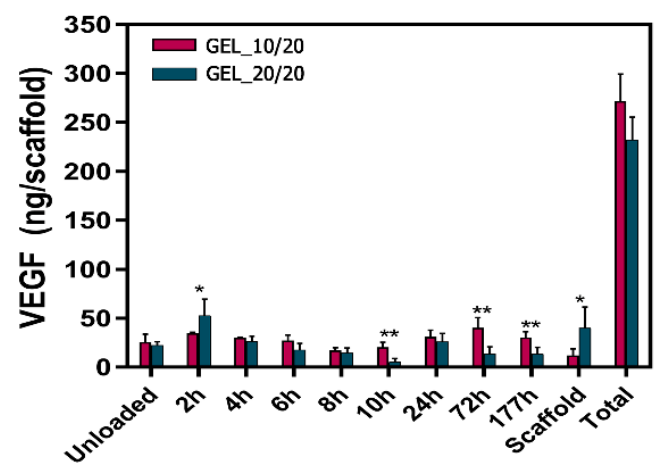

C

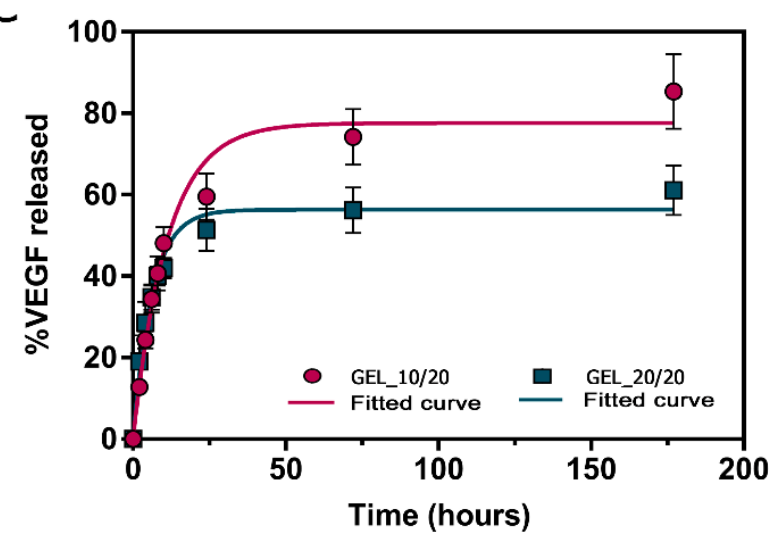

B

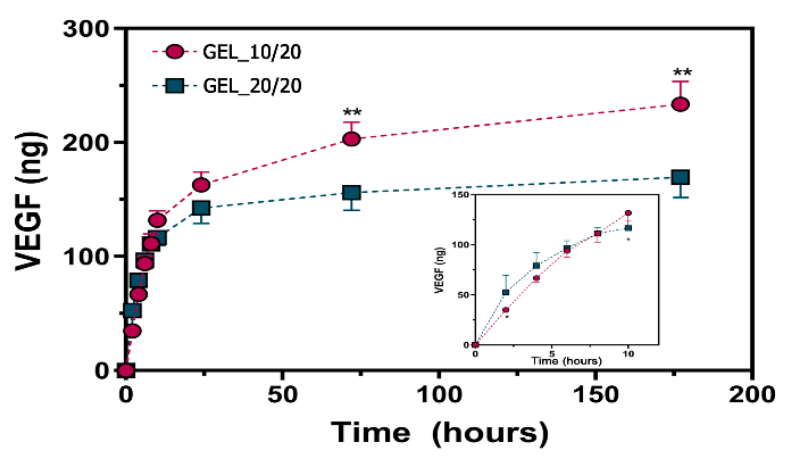

D

\begin{tabular}{|l|c|c|c|c|c|}
\cline { 2 - 5 } \multicolumn{1}{c|}{} & \multicolumn{2}{c|}{ \% VEGF } & \multicolumn{2}{c|}{ K $_{\text {released }} \boldsymbol{\infty}$} & \multicolumn{2}{c|}{ R $^{\mathbf{2}}$} & \multicolumn{1}{c|}{} \\
\cline { 2 - 6 } \multicolumn{1}{c|}{} & Best fit value & $95 \% \mathrm{CI}$ & Best fit value & $95 \% \mathrm{CI}$ & \\
\hline GEL_10/20 & 77.59 & $73.38-81.81$ & 0.089 & $0.076-0.102$ & \multirow{2}{*}{0.9496} \\
\hline GEL_20/20 & 56.34 & $53.38-59.31$ & 0.160 & $0.135-0.185$ & 0.9352 \\
\hline
\end{tabular}


A
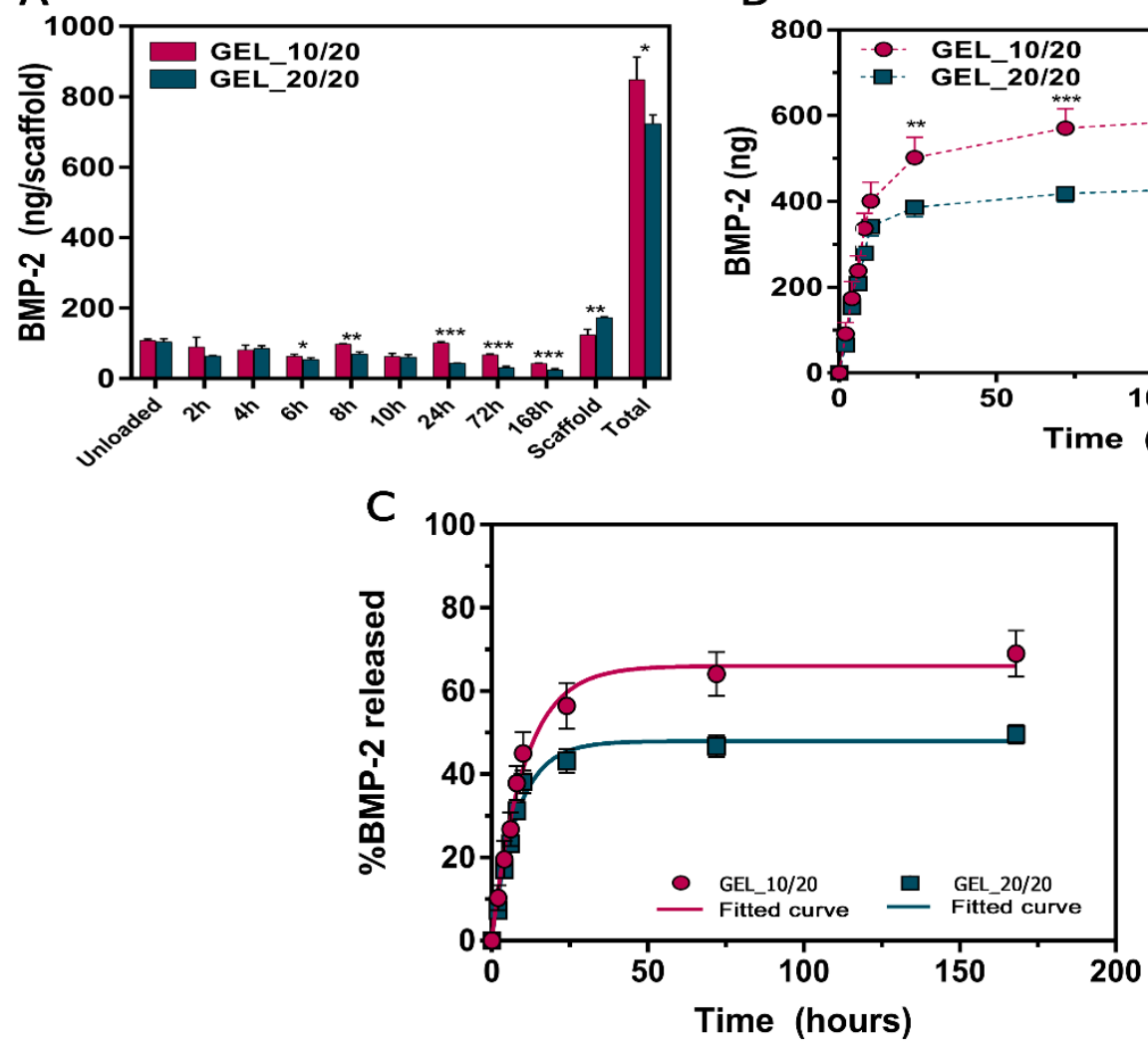

B

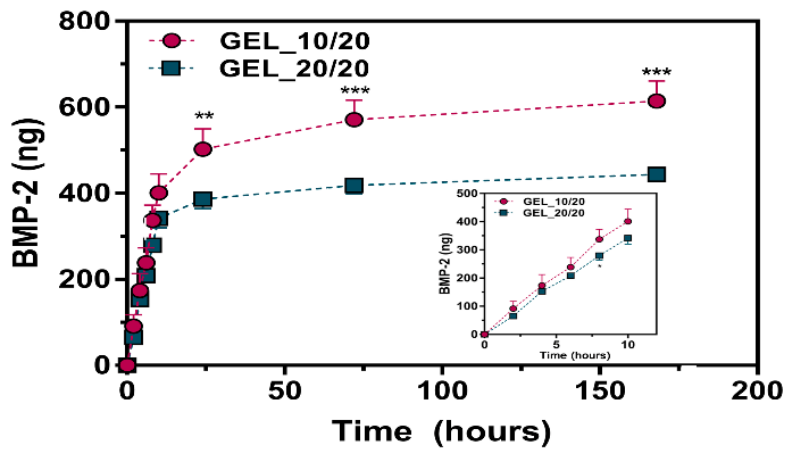

\begin{tabular}{|c|c|c|c|c|c|}
\cline { 2 - 5 } \multicolumn{1}{c|}{} & \multicolumn{2}{c|}{ \% BMP-2 released $\boldsymbol{\infty}$} & \multicolumn{2}{c|}{ K (hour ${ }^{-1}$ ) } & \multirow{2}{*}{$\mathbf{R}^{\mathbf{2}}$} \\
\cline { 2 - 6 } \multicolumn{1}{c|}{} & Best fit value & $95 \% \mathrm{CI}$ & Best fit value & $95 \% \mathrm{CI}$ & \\
\hline GEL_10/20 & 66.05 & $62.90-69.20$ & 0.097 & $0.085-0.110$ & 0.961 \\
\hline GEL_20/20 & 47.97 & $46.11-49.82$ & 0.123 & $0.109-0.136$ & 0.9723 \\
\hline
\end{tabular}
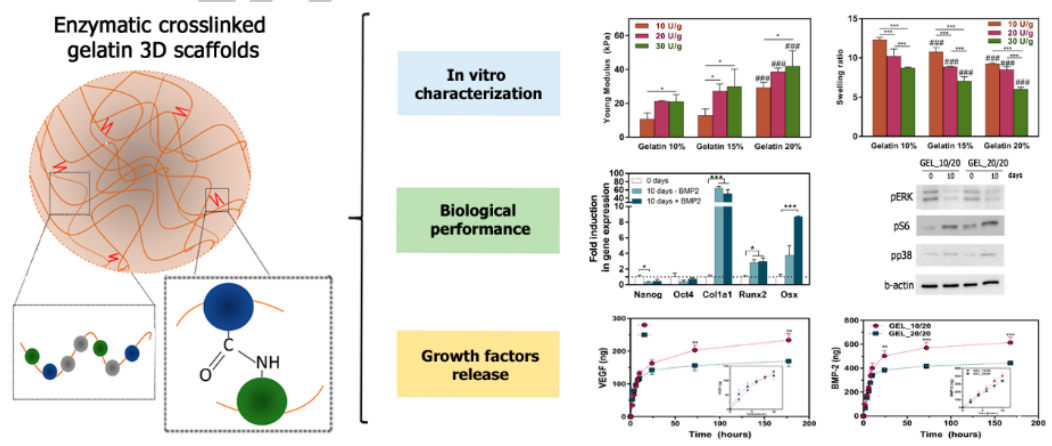

Vitoria-Gasteiz, February $18^{\text {th }} 2019$

Ms. Ref. No.: IJP-D-18-02617 
The conflict of interest document was already submitted in the initial submission process together with the remaining figures.

Thanks in advance.

\section{Gorka Orive Arroyo}

Associate Professor of Pharmacy \& Pharmaceutical Technology

University of the Basque Country (UPV/EHU)

gorka.orive@ehu.eus 